\title{
ANDRAGOGIA: CONTRIBUIÇÕES PARA A APRENDIZAGEM DO ADULTO PROFESSOR
}

\author{
ANDRAGOGY: CONRIBUTIONS \\ FOR ADULT TEACHER LEARNING
}

\author{
ANDRAGOGIA: CONTRIBUCIONES PARA \\ EL APRENDIZAJE DEL ADULTO PROFESOR
}

\begin{abstract}
Amanda Cibele Soares ${ }^{1}$
Rita de CÁssia de Alcântara Braúna ${ }^{2}$

Ana Cláudia Lopes Chequer Saraiva ${ }^{3}$

${ }^{1}$ Universidade Federal de Viçosa (UFV), Viçosa/MG-Brasil

${ }^{2}$ Universidade Federal de Viçosa (UFV), Viçosa/MG-Brasil

${ }^{3}$ Universidade Federal de Viçosa (UFV), Viçosa/MG-Brasil
\end{abstract}

Resumo Este artigo é fruto de uma dissertação de mestrado concluída em 2018 que se propôs a investigar as especificidades da aprendizagem de pessoas adultas, particularmente as relativas ao adulto no contexto do Ensino Superior, no intuito de conhecer e compreender os pressupostos teóricos e conceituais que orientam a aprendizagem desse público, para, a partir desse conhecimento, buscar contribuições para o campo de formação de professores, que é constituído por indivíduos adultos. A referida pesquisa é de natureza qualitativa, adotando como metodologia a Pesquisa Bibliográfica. Estabelecemos como fonte de consulta os bancos de dados da CAPES; SciELO; ANPEd; ENDIPE e CNFP, investigando pesquisas científicas produzidas do ano 2000 ao ano 2016. Neste artigo, nos restringimos à Andragogia, umas das teorias abordadas na referida pesquisa de mestrado. A teoria andragógica apresenta interessantes considerações sobre a aprendizagem do indivíduo adulto, as quais podem se converter em significativas contribuições para o campo de formação de professores.

Palavras-chave: Andragogia; Aprendizagem do adulto; Formação de professores.

Abstract This article is the result of a master thesis concluded in 2018, which intended to investigate the specificities of adult learning, particularly those related to the adult in the Higher Education context, in order to know and understand the theoretical and conceptual 
presuppositions that guide this public learning, to, from this knowledge, seek contributions to the field of teacher training, which is constituted by adult individuals. This research has a qualitative nature, where was adopted the bibliographic research methodology. We have established the CAPES; SciELO; ANPEd; ENDIPE and CNFP databases as a source of inquiry, investigating scientific researches produced from 2000 to 2016.In this article we restrict ourselves to Andragogy, one of the theories addressed in the aforementioned master's research. This theory presents interesting considerations on the individual adult learning that can turn in significant contributions to the field of teacher training.

Keywords: Andragogy; AdUlt learning; Teacher training.

Resumen Este artículo es fruto de una disertación de maestría concluida en 2018 que se propuso investigar las especificidades del aprendizaje de personas adultas, particularmente las relativas al adulto en el contexto de la Enseñanza Superior, con el fin de conocer y comprender los presupuestos teóricos y conceptuales que orientan la enseñanza el aprendizaje de este público, para, a partir de este conocimiento, buscar contribuciones al campo de formación de profesores, que está constituido por individuos adultos. La referida investigación es de naturaleza cualitativa, adoptando como metodología la Investigación Bibliográfica. Establecemos como fuente de consulta los bancos de datos de CAPES; SciELO; ANPED; ENDIPE y CNFP, investigando investigaciones científicas producidas del año 2000 al año 2016. En este artículo nos restringimos a la Andragogia, unas de las teorías abordadas en la referida investigación de maestría. La teoría andragógica presenta interesantes consideraciones sobre el aprendizaje del individuo adulto, que pueden convertirse en significativas contribuciones al campo de formación de profesores.

Palabras clave: Andragogia; Aprendizaje del adulto; Formación de profesores.

\section{INTRODUÇÃo}

Este artigo é fruto de uma dissertação de mestrado na qual foi realizada uma pesquisa bibliografia, tendo como objeto de estudo a aprendizagem do adulto. No referido estudo, foram investigadas as especificidades da aprendizagem de pessoas adultas, particularmente as relativas ao adulto no contexto do ensino superior, no intuito de conhecer e compreender os pressupostos teóricos e conceituais que orientam a aprendizagem desse público, para, a partir desse conhecimento, buscar contribuições para o campo de formação de professores, que é constituído por indivíduos adultos.

A aprendizagem tem sido tema de interesse de várias ciências, considerando a centralidade desse processo no desenvolvimento humano. Contudo, definir a aprendizagem não é algo simples. Ela tem sido objeto de estudo de várias abordagens teóricas, trazendo aspectos e elementos diferenciados do aprender.

Com interesse especial pela aprendizagem na fase adulta, a Andragogia é uma das teorias que se dedicam à investigação da aprendizagem. Malcolm Knowles, principal re- 
presentante dessa abordagem, considera ser difícil definir claramente a aprendizagem. Para demonstrar essa dificuldade, Knowles, Holton e Swanson (2009) recorrem às palavras de Smith (1982):

Já foi sugerido que o termo aprendizagem desafia uma definição precisa, pois ele é aplicado em múltiplos contextos. Aprendizagem é usada para se referir a (1) aquisição e domínio do que já é conhecido sobre algo, (2) extensão e esclarecimento do significado da experiência de uma pessoa, ou (3) um processo organizado e intencional de testar ideias relevantes para os problemas. Em outras palavras, ele é usado para descrever um produto, processo ou função (SMITH, 1982 citado por KNOWLES; HOLTON; SWANSON, 2009, não paginado).

Como podemos observar em Knowles, Holton e Swanson (2009), não existe uma definição única de aprendizagem capaz de contemplar toda a sua complexidade. Contudo, um dos pontos centrais sobre a aprendizagem é que esta envolve a aquisição ou construção de novos conhecimentos, independentemente das diferentes compreensões a respeito de como esses novos conhecimentos são adquiridos e dos elementos envolvidos nesse processo.

A pesquisa realizada teve como interesse investigar a aprendizagem do adulto no contexto do ensino superior, como esse tema tem sido abordado em pesquisas acadêmicas do campo de formação de professores e quais os apontamentos e contribuições que as teorias da aprendizagem podem trazer para a formação docente.

Nosso interesse de pesquisa encontrou ancoragem nos estudo de Garcia (1999, p. 49), importante estudioso do campo de formação e professores, que nos fala sobre a "utilidade de se aplicar os estudos sobre aprendizagem e o desenvolvimento adulto na formação de professores". O autor nos chama a atenção para o fato relevante de que os alunos dos cursos de formação de professores, os licenciandos, também se enquadram nos estudos sobre aprendizagem do adulto, pois também são indivíduos adultos envolvidos em processos de aprendizagem.

Nesse sentido, compreendendo as especificidades da aprendizagem do aluno adulto como um importante aspecto a ser considerado nos cursos de formação docente, Garcia (1999) destaca a Andragogia, entre as teorias da aprendizagem, como um possível caminho a ser seguido:

Em relação à aprendizagem das pessoas adultas, e não nos devemos esquecer que os professores o são, não se pode afirmar que exista uma única teoria da aprendizagem do adulto. A teoria da aprendizagem do adulto que com maior frequência se tem comentado em relação à aprendizagens dos professores parece ser a "andragogia", proposta por Knowles, e definida como a "a arte e a ciência de ajudar os adultos a aprender" (GARCIA, 1999, p. 55).

Desse modo, a andragogia tem sido vista por alguns autores, como Garcia (1999), como uma teoria para auxiliar o ensino-aprendizado de pessoas em idade adulta, incluindo professores e futuros professores, por se tratar de uma teoria criada especialmente para o trabalho com o público adulto, conforme abordaremos neste artigo. 
Este artigo se encontra estruturado em cinco seções. A primeira introduz o objeto de pesquisa e os objetivos do estudo; a segunda define o conceito de Andragogia procurando estabelecer relações com o campo da formação de professores; a terceira seção apresenta o percurso metodológico, descrevendo a Pesquisa Bibliográfica realizada; a quarta focaliza os resultados alcançados pela pesquisa; e na seção cinco, procuramos apontar quais as contribuições que os estudos sobre a aprendizagem do adulto realizados na perspectiva da andragogia podem trazer para a formação de professores.

\title{
ANDRAGOGIA: APROXIMAÇÕES COM A FORMAÇÃo DE PROFESSORES
}

Para entendermos melhor o conceito de Andragogia, voltemos no tempo até os primeiros pensamentos que lhe deram origem. Segundo Vogt e Alves (2005), o termo andragogia foi criado em 1833, pelo professor alemão Alexandre Kapp. Esse termo ficou por um longo período esquecido e voltou a ser empregado, em 1921, no relatório de Rosenstock, ${ }^{1}$ o qual sinalizava que a educação de adultos necessita de métodos próprios. De acordo com Knowles, Holton e Swanson (2009), Lindeman, em 1926, refletindo acerca dos métodos de ensino existentes, e buscando melhores formas de educar pessoas adultas, fez declarações visionárias como:

\begin{abstract}
A abordagem para a educação de adultos ocorrerá por meio de situações, e não de disciplinas. Nosso sistema acadêmico se desenvolveu na ordem inversa: as disciplinas e os professores são o ponto de partida; os alunos vêm em segundo lugar. Na educação convencional, espera-se que o aluno ajuste-se a um currículo estabelecido; na educação de adultos, o currículo é construído em torno das necessidades e dos interesses do aluno. Cada adulto se vê em situações específicas em relação a seu trabalho, lazer, vida em família, vida em comunidade etc. - situações que pedem ajustes. É nesse ponto que se inicia a educação de adultos. O assunto é trazido para a situação, é posto em prática quando necessário. Os materiais didáticos e os professores desempenham um papel novo e secundário nesse tipo de educação; eles devem ceder lugar à importância primária dos aprendizes (LINDEMAN, 1926 citado por KNOWLES; HOLTON; SWANSON, 2009, não paginado).
\end{abstract}

Dando sequência às suas reflexões sobre a forma de aprender do adulto, Knowles, Holton e Swanson (2009) dizem que Lindeman (1926) defende a experiência do aprendiz como principal recurso na educação de pessoas adultas. Segundo esse autor, “(...) a experiência é o livro didático vivo do adulto aprendiz" (LINDEMAN, 1926 citado por KNOWLES; HOLTON; SWANSON, 2009, não paginado).

1 Relatório feito pelo cientista social alemão Eugene Rosenstock para a Academia do Trabalho, em Frankfurt, onde lecionava. Nesse relatório, argumentou que a educação de pessoas adultas necessita de professores, métodos e filosofia diferenciados, utilizando o termo andragogia para se referir a essas exigências especiais. 
Apesar de passados quase dois séculos desde a formulação do termo andragogia, em 1833, foi a partir de 1970 que a andragogia, como teoria ou sistema de ideias, ganhou notoriedade. A contar desse ano, Malcolm Knowles, influenciado pelos pensamentos de Lindeman, publicou, nos Estados Unidos, várias obras abordando a aprendizagem do adulto, entre elas "The Adult Learner - A Neglected Species" (1973), assim, introduzindo e definindo o termo ANDRAGOGIA, como sendo a arte e ciência de orientar adultos a aprender. Malcolm Knowles se tornou uma das principais referências acerca da temática da andragogia e da aprendizagem do adulto, sendo por muitos considerado o "pai da andragogia" (VOGT; ALVES, 2005; KNOWLES; HOLTON; SWANSON, 2009).

Segundo Knowles, Holton e Swanson (2009), atualmente existem seis hipóteses ou princípios fundamentais da andragogia, conforme Quadro 1 a seguir. São eles: 1) Necessidade de saber; 2) Autoconceito do aprendiz (autodireção); 3) Experiência do aprendiz; 4) Prontidão do aprendiz; 5) Orientação à aprendizagem; e 6) Motivação para aprender (interna).

Quadro1 - Modelo andragógico na prática.

\begin{tabular}{|c|c|l|}
\hline PRINCÍPIOS & INDICADORES & \multicolumn{1}{c|}{ CARACTERIZAÇÃO } \\
\hline $\begin{array}{c}\text { 1- Necessidade } \\
\text { de saber }\end{array}$ & $\begin{array}{c}\text { O porquê } \\
\text { O quê } \\
\text { Como }\end{array}$ & $\begin{array}{l}\text { Os adultos precisam saber por que eles precisam } \\
\text { aprender algo antes de aprendê-lo. }\end{array}$ \\
\hline $\begin{array}{c}\mathbf{2}-\text { Autoconceito } \\
\text { do aprendiz } \\
\text { (autodireção) }\end{array}$ & $\begin{array}{c}\text { Autônomo } \\
\text { Autodirigido }\end{array}$ & $\begin{array}{l}\text { A autopercepção dos adultos é altamente dependente } \\
\text { de um movimento rumo à autodireção. }\end{array}$ \\
\hline $\begin{array}{c}\mathbf{3}-\text { Experiência } \\
\text { do aprendiz }\end{array}$ & $\begin{array}{c}\text { Recurso/ } \\
\text { Modelos mentais }\end{array}$ & $\begin{array}{l}\text { As experiências prévias do aprendiz fornecem } \\
\text { riqueza de recurso para a aprendizagem. }\end{array}$ \\
\hline $\begin{array}{c}\mathbf{4}-\text { Prontidão do } \\
\text { aprendiz (tarefas } \\
\text { cotidianas) }\end{array}$ & $\begin{array}{c}\text { Relacionado à } \\
\text { vida/ }\end{array}$ & $\begin{array}{l}\text { Tarefa de } \\
\text { Os adultos tipicamente se tornam prontos para } \\
\text { aprender quando experienciam a necessidade de lidar } \\
\text { com uma situação de vida ou realizar uma tarefa. }\end{array}$ \\
\hline $\begin{array}{c}\mathbf{5}-\text { Orientação à } \\
\text { aprendizagem }\end{array}$ & $\begin{array}{c}\text { Centrado no } \\
\text { problema/ } \\
\text { Contextual }\end{array}$ & $\begin{array}{l}\text { Aorientação de aprendizagem de adultos é centrada na } \\
\text { vida; a educação é um processo de desenvolvimento } \\
\text { dos níveis de competências para que atinjam seu } \\
\text { potencial complexo. }\end{array}$ \\
\hline $\begin{array}{c}\text { 6- Motivação } \\
\text { para aprender } \\
\text { (interna) }\end{array}$ & $\begin{array}{c}\text { Valor Intrínseco/ } \\
\text { Recompensa } \\
\text { pessoal }\end{array}$ & $\begin{array}{l}\text { A motivação para a aprendizagem dos adultos é mais } \\
\text { interna do que externa. }\end{array}$ \\
\hline
\end{tabular}

Fonte: Construção das autoras com base em KNOWLES; HOLTON; SWANSON (2009).

A andragogia apresenta características distintas do modelo pedagógico tradicional. Segundo Knowles, Holton e Swanson (2009, n. p), "a educação de adultos é uma tentativa de descobrir um novo método e criar um novo incentivo para a aprendizagem". Assim, refletindo sobre a andragogia, de acordo com Carvalho et al., 2010): 
No contexto da andragogia, a aprendizagem adquire uma característica mais centrada no aluno, na independência e na autogestão da aprendizagem. Pessoas aprendem o que realmente precisam saber (aprendizagem para aplicação prática na vida diária), sendo a experiência uma rica fonte de aprendizagem, através da discussão e da solução de problemas em grupo (CARVALHO et al., 2010, p. 88).

Muito do poder e atratividade da andragogia consiste em sua versatilidade de aplicação. "Ela é um conjunto de princípios de aprendizagem de adultos que se aplicam a todas as situações de aprendizagem de adultos" (KNOWLES; HOLTON; SWANSON 2009, não paginado). Segundo os autores, os princípios andragógicos não se restringem ao contexto acadêmico, eles podem ser adaptados aos objetivos e propósitos de diversas áreas de aprendizagem que envolvam adultos.

Assim, é justamente essa versatilidade da teoria andragógica, aliada à sua fundamentação especialmente direcionada à aprendizagem na fase adulta, que faz que essa abordagem possa ser uma relevante teoria para pensarmos o campo de formação de professores, tendo em vista que os professores são sujeitos adultos em constante processo de aprendizagem.

Voltando nossa atenção para o campo de formação de professores e os elementos que o constituem, de acordo com Garcia (1999), sendo a atividade de ensino, o exercício da docência, uma profissão, se faz necessário, assim como em outras profissões, uma preparação adequada para exercê-la. Tal preparação deve promover o domínio adequado da ciência, técnica e da arte desse ofício, ou seja, a competência profissional. Garcia (1999) conceitualiza o campo de formação de professores:

\footnotetext{
A Formação de Professores é a área de conhecimentos, investigações e de propostas teóricas e práticas que, no âmbito da Didática e da Organização Escolar, estuda os processos através dos quais os professores - em formação ou em exercício - se implicam individualmente ou em equipe, em experiências de aprendizagem através das quais adquirem ou melhoram os seus conhecimentos, competências e disposições, e que lhes permite intervir profissionalmente no desenvolvimento do seu ensino, do currículo e da escola, com o objetivo de melhorar a qualidade da educação que os alunos recebem (GARCIA, 1999, p. 26).
}

O campo da formação de professores é, com frequência, envolvido em inúmeras discussões sobre temas relacionados ao fazer docente, como: políticas educacionais; atratividade da carreira docente; saberes docentes; formação continuada e outros. Todas essas discussões objetivam, de variados modos, melhorias na qualidade educacional como um todo. A temática da inserção da andragogia se apresenta como mais uma questão a ser discutida pela formação de professores, considerando ser a arte e a ciência de orientar adultos a aprender (KNOWLES; HOLTON; SWANSON, 2009, não paginado).

Segundo Vaillant e Marcelo (2012, p. 23), "preparar docentes é formar adultos". Nesse sentido, independentemente se os futuros professores ou já professores vão lecionar para crianças, adolescentes, jovens ou adultos, o público dos cursos de formação de professores é, predominantemente, constituído por indivíduos na fase adulta, e essa característica não deve ser ignorada na condução da formação docente. 
De acordo com Mizukami (2002, p. 49), "aprender a ensinar é também um processo complexo que envolve fatores afetivos, cognitivos, éticos, de desempenho, dentre outros". Assim, para o professor formador, envolvido com a formação de futuros professores, também se faz necessário se ajustar às especificidades de seus alunos, buscar métodos adequados para ensinar adultos, compreendendo que "assim como são diferentes as formas de aprender, devem ser diferentes também as formas de ensinar" (VEIGA; ÁVILA, 2012, p. 26).

Conforme argumentam Placco e Souza (2015), no contexto da aprendizagem do adulto professor, o papel do formador consiste em identificar as necessidades e interesses dos alunos para atuar com mais clareza e coerência. De acordo com essas autoras, o formador deve atuar como um líder do grupo de professores aprendizes, sendo ele o desencadeador das aprendizagens e o responsável por incentivar os processos de autoformação.

Complementando essas ideias, de acordo com Noffs e Rodrigues (2011), a andragogia, como modelo educacional de adultos, tem seu foco direcionado para o processo de aprendizagem e não para o conteúdo. Contudo, entendemos que os conteúdos continuam tendo papel importante, pois se referem ao que será ensinado aos aprendizes, entretanto, nessa perspectiva teórica o conteúdo não é o foco, o ensino não é direcionado a partir de conteúdos estabelecidos previamente. Na andragogia, a orientação da aprendizagem parte de situações da vida, aprendizados a partir das experiências e necessidades apresentadas pelo aprendiz, não de temas preestabelecidos.

Nessa abordagem, a metodologia visa promover a participação ativa dos alunos, em uma relação horizontal entre professor e aluno, na qual o professor assume o papel de facilitador do processo de aprendizagem.

Seguindo a perspectiva andragógica do professor como um facilitador, como um motivador de pessoas e aprendizados, um agente de transformação, Perissé (2008) afirma:

\footnotetext{
Os conceitos andragógicos devem ser aplicados na formação do professor, uma vez que o professor é adulto e necessita ver e tratar seus alunos adultos como pessoas verdadeiramente livres e responsáveis. Esta é a motivação das motivações - ser tratado como um ser inteligente, capaz de acertar na vida. Muito além das notas, os alunos maduros anseiam ver como a realidade acadêmica concorrerá de fato para que sua realidade pessoal seja dinâmica, produtiva (PERISSÉ, 2008, não paginado).
}

Corroborando os pensamentos de Perissé (2008), de acordo com Knowles, Holton e Swanson (2009), os estudos sobre a aprendizagem do adulto indicam que, nessa fase, os indivíduos tendem a sentir maior necessidade de se mostrarem independentes e se sentem insatisfeitos e desestimulados quando se veem obrigados a ceder aos desejos de outra pessoa, especialmente se sua opinião e interesses não são considerados. O adulto se sente motivado a aprender algo quando entende o sentido daquele aprendizado, quando consegue perceber as vantagens e benefícios que esse conhecimento poderá lhe trazer, como também os prejuízos que a falta desse aprendizado pode acarretar em sua vida. Portanto, é de extrema importância para a motivação dos adultos que os aprendizados e ensinamentos estejam sincronizados com a vida real. 
Garcia (1999), tendo apontado a teoria andragógica, proposta por Knowles, como a teoria da aprendizagem do adulto mais comentada em relação à aprendizagem dos professores diz que, "se lermos com atenção os princípios da Andragogia, dar-nos-emos conta da importância que podem ter para entender, explicar, planificar e desenvolver a Formação de Professores" (GARCIA, 1999, p. 55). Entendemos que, na compreensão desse autor, os princípios da andragogia, por terem sido formulados especificamente como foco no aprendiz adulto, podem auxiliar na aprendizagem dos futuros docentes, já que são indivíduos adultos. Além disso, os seis princípios da teoria andragógica oferecem uma explicação acerca de como a aprendizagem do adulto acontece e quais são os principais aspectos que devem ser levados em consideração na condução da aprendizagem. Seguindo essa compreensão, as hipóteses desenvolvidas pela teoria andragógica podem auxiliar o professor formador a planejar sua ação, assim, pelo que nos indica a fala do autor, a aprendizagem dos futuros professores seria favorecida, trazendo benefícios para a formação de professores.

Corroborando os argumentos de Garcia (1999), de acordo com Vogt e Alves (2005), os princípios e a metodologia andragógica propostos por Knowles apresentam-se como uma possibilidade de repensar o fazer do professor, podendo oferecer contribuições para uma atuação mais ajustada às necessidades e capacidades do aluno adulto.

\section{Percurso metodológico}

Este foi um estudo de natureza qualitativa, sendo a investigação desenvolvida a partir de uma Pesquisa Bibliográfica. De acordo com Gil (2002, p. 44), “a pesquisa bibliográfica é desenvolvida com base em material já elaborado, constituído principalmente de livros e artigos científicos". Esse tipo de pesquisa tem como objeto de investigação produções acadêmicas variadas, expressas em diferentes formatos (livro, tese, dissertação, artigo etc.) e localizadas em variados bancos de dados.

A pesquisa bibliográfica possibilita ao pesquisador entrar em contato com amplo conteúdo que já foi produzido e registrado a respeito do seu tema de pesquisa, podendo ter acesso a produções de inúmeros teóricos que se dedicam à temática.

Nesse sentido, as fontes de dados consultadas nesta pesquisa foram: dissertações e teses publicadas no banco de dados da CAPES, ${ }^{2}$ artigos disponibilizados no banco de periódicos da SciELO, ${ }^{3}$ anais de eventos da ANPEd, ${ }^{4}$ ENDIPE $^{5}$ e CNFP. ${ }^{6}$

2 Coordenação de Aperfeiçoamento de Pessoal de Nível Superior (CAPES) é uma fundação vinculada ao Ministério da Educação do Brasil que atua na expansão e consolidação da pós-graduação stricto sensu (mestrado e doutorado) em todos os Estados da Federação.

3 A Scientific Electronic Library Online (SciELO ) é uma biblioteca eletrônica que abrange uma coleção selecionada de periódicos científicos brasileiros.

4 ANPEd - Associação Nacional de Pós-Graduação e Pesquisa em Educação. Congrega programas de pós-graduação stricto sensu (mestrado e doutorado) em Educação.

5 ENDIPE - Encontro Nacional de Didática e Práticas de Ensino. É um encontro bianual que congrega pesquisadores, especialistas, dirigentes educacionais, professores e estudantes dos mais distintos espaços do país e do exterior para discutir a didática e as práticas de ensino.

6 CNFP - Congresso Nacional de Formação de Professores. Evento realizado na cidade de Águas de Lindóia-SP, pela Universidade Estadual Paulista (UNESP). 
Como critério de seleção do material de investigação, partimos da análise dos títulos, palavras-chave, leitura dos resumos e referências bibliográficas dos referidos materiais bibliográficos, sendo selecionadas apenas produções relacionadas às temáticas da aprendizagem do jovem e adulto e a formação de professores. Foram investigadas produções nacionais publicadas a partir do ano 2000 ao ano 2016.

Nesse sentido, para analisarmos como a aprendizagem do jovem e adulto tem sido abordada em produções acadêmicas do campo da educação, identificando interlocuções e contribuições para o campo de formação de professores, foi realizado um mapeamento das pesquisas científicas selecionadas. Buscou-se identificar as teorias que orientam esses estudos, os elementos centrais que fundamentam a aprendizagem do adulto nesses trabalhos e quais as possíveis articulações e apontamentos para a formação docente.

\section{Categorias teóRICAS IDENTIFICADAS E CONTRIBUiÇões PARA O CAMPO DE FOR- MAÇÃO DE PROFESSORES}

Neste estudo, foram selecionadas 35 pesquisas científicas para compor a investigação. $\mathrm{Na}$ análise das produções, buscamos identificar as categorias teóricas mais representativas que fundamentam as discussões desenvolvidas sobre a aprendizagem do adulto, no período recortado de 2000 a 2016.

Aqui, nos concentrando na perspectiva Andragógica, ${ }^{7}$ encontramos ao todo nove categorias teórico-conceituais representativas dessa abordagem. Foram elas: 1) Experiência; 2) Prontidão do aprendiz; 3) Aplicação Imediatista; 4) Motivação interna; 5) Autoconceito do aprendiz; 6) Autonomia; 7) Necessidade de Saber; 8) Resolução de problemas; 9) Professor facilitador. Essas foram as categorias teóricas referentes à andragogia mais acessadas nas 35 pesquisas analisadas.

A experiência foi a categoria mais representativa de nossa amostra analisada, ${ }^{8}$ tendo sido destacada em 17 produções, o que corresponde a 48,57\% das pesquisas acadêmicas investigadas.

A experiência aparece nas pesquisas estudadas como um elemento central para a compreensão da aprendizagem do indivíduo adulto. Na abordagem Andragógica, a experiência é compreendida como o principal recurso na aprendizagem do adulto. Conforme apresentado por Malcolm Knowles, principal representante dessa teoria, “(...) a experiência é o livro didático vivo do adulto aprendiz" (LINDERMAN, 1926 citado por KNOWLES; HOLTON; SWANSON, 2009, não paginado).

A experiência do aprendiz, além de ser considerada uma fundamental fonte de aprendizagem dos adultos onde novos aprendizados podem ser ancorados e desenvolvidos, segundo Knowles, Holton e Swanson (2009), as experiências têm íntima relação com a autoidentidade do aprendiz, constituem quem eles são. Nesse sentido, desprezar as expe-

\footnotetext{
7 Na dissertação que deu origem a este artigo foram estudadas também outras três abordagens teóricas, além da Andragogia: Teoria Sócio-Histórica; Epistemologia Genética; e Teoria da Aprendizagem Experiencial.

8 Incluindo as outras três teorias abordadas na dissertação.
} 
riências anteriores desses aprendizes é como se o professor formador estivesse rejeitando, desconsiderando o próprio aluno e quem ele é.

Conforme podemos concluir a partir dos trabalhos analisados, é de grande importância que os professores formadores busquem conhecer e levem em consideração as experiências prévias de seus alunos, pois elas podem fornecer ao professor formador inúmeras informações a respeito desses alunos e indicadores para orientar sua atuação docente, por exemplo, podem apontar os conhecimentos que o aluno já possui, seus gostos e interesses, oportunidades que teve, habilidades desenvolvidas, enfim, um histórico pessoal e profissional que pode ser usado a favor da aprendizagem atual.

Pelos elementos expostos, podemos concluir que a experiência é uma das categorias mais importantes a ser considerada quando se trata de aprendizagem de pessoas adultas. A bagagem de experiências trazidas pelo adulto vai refletir em sua relação com a aprendizagem. De acordo com um dos trabalhos analisados intitulado "Formação de professores em processos andragógicos de ensino e aprendizagem":

É fundamental a existência de uma formação de professores capaz de conscien-
tizá-los a adotarem uma didática e uma docência voltadas, especificamente,
para o modo como os adultos aprendem, em que esses professores considerem
as especificidades que o aluno adulto traz em seus conhecimentos prévios, ex-
periências, características individuais e do grupo adulto como um todo (DA-
GOSTINO, 2011, p. 27).

Portanto, o professor não deve negligenciar a experiência anterior de seu aluno, pois ela estará, de alguma forma, influenciando o desempenho do adulto aprendiz, ainda que não seja abordada. Sendo assim, mais do que não ignorar as experiências anteriores, os professores formadores podem utilizar as experiências passadas de seus alunos como recursos para favorecer seu aprendizado, tendo em vista a relevância dessa categoria nos estudos analisados sobre aprendizagem do adulto.

A Prontidão do aprendiz foi destacada em quatro trabalhos, o que corresponde a $11,42 \%$ da nossa amostra. Refere-se à predisposição para aprender do adulto. De acordo com a teoria andragógica, pessoas adultas se tornam mais abertas para aprender quando experienciam a necessidade de lidar com uma situação de vida ou realizar uma tarefa.

Entre as pesquisas selecionadas, a dissertação desenvolvida por Azevedo (2009), "Educação à distância: estudo comparativo do perfil e motivações dos alunos das instituições de ensino superior e das organizações corporativas" argumenta sobre a prontidão do aprendiz:

O adulto está pronto para aprender o que decide aprender. Sua seleção de aprendizagem é natural e realista. Em contrapartida, ele se nega a aprender o que outros lhe impõem como sua necessidade de aprendizagem (AZEVEDO, 2009, p. 69).

Pelos elementos apresentados no fragmento desta pesquisa analisada, podemos entender que para a aprendizagem do adulto acontecer ele necessita estar aberto a ela, pronto, disposto a aprender. Para que haja essa prontidão do adulto aprendiz, o conteúdo a ser 
aprendido deve ser relevante para esse aluno, ele deve conseguir compreender a necessidade e utilidade desse conhecimento para a sua vida.

Com relação à formação de professores, é importante que o professor formador consiga demonstrar a utilidade e relevância dos conteúdos ensinados aos futuros docentes. Para se envolver realmente com a sua aprendizagem, os docentes em formação necessitam vislumbrar a necessidade real daquele conhecimento para a sua atuação profissional, não basta apenas que alguém lhe diga que é importante, essa compreensão deve ser feita pelo próprio sujeito da aprendizagem.

Aplicação Imediatista, essa categoria conceitual é desenvolvida e explicada na Teoria Andragógica, tendo sido acessada em quatro trabalhos. Refere-se à aprendizagem centrada na atuação, na necessidade que o adulto tem de aprender conteúdos que sejam relevantes para a sua vida atual, conhecimentos que possam ser empregados a curto prazo.

A respeito da necessidade do adulto de aplicação dos novos aprendizados no seu cotidiano, o trabalho analisado "Do acolhimento ao acompanhamento compartilhado: A construção colaborativa de uma proposta para o estágio curricular no curso de pedagogia" - inspirado nos pressupostos formulados por Knowles (1980) argumenta sobre a aprendizagem do adulto:

(...) a perspectiva de tempo muda de uma aplicação futura do conhecimento para o de uma aplicação imediatista, e consequentemente, a concepção que o indivíduo tem sobre sua aprendizagem é modificada, passando de uma aprendizagem centrada no sujeito, para aquela centrada na atuação (CYRINO, 2016, p. 252).

Refletindo sobre o conceito de aplicação imediatista podemos inferir que os alunos dos cursos de formação de professores, enquanto aprendizes adultos que são, também anseiam por um aprendizado centrado na atuação, que seja conectado de forma mais direta com a prática docente, um aprendizado que lhes capacite para lidar com situações reais do dia a dia da profissão e que possa ser aplicado a curto prazo.

A Motivação Interna, categoria acessada por quatro trabalhos, é uma das características da aprendizagem do adulto na abordagem Andragógica. De acordo com esse aporte teórico, a motivação para a aprendizagem dos adultos é mais interna do que externa. Ele ainda responde a fatores externos, mas se motiva especialmente a partir de fatores internos, como o desejo de autorrealização, satisfação pessoal, autoestima e a resolução de problemas e dificuldades enfrentadas na sua vida diária.

Como apresentado no estudo selecionado de Dagostino (2012, p. 6), "a continuidade da motivação do adulto em aprender novos conhecimentos está relacionada a real aplicação do que foi aprendido com o seu cotidiano de vida (...)". Essa fala do autor relaciona a motivação do adulto a outro importante conceito identificado em nossa pesquisa e já abordado aqui: a aplicação imediatista.

Grande parte da motivação do adulto para aprender está ligada à utilidade que o aprendizado terá em sua vida pessoal ou profissional. Essa compreensão da motivação do adulto nos leva a entender que, na formação de professores, os futuros docentes também se sentem 
mais motivados e interessados a aprender um conteúdo quando visualizam a utilidade desse conhecimento na sua atuação prática profissional.

O autoconceito do aprendiz foi uma categoria acessada por quatro estudos. Também nomeado de autodireção, o autoconceito do aprendiz se refere à sua autopercepção, ou seja, a percepção que o adulto tem sobre si mesmo. Os adultos, de acordo com essa abordagem teórica, possuem um autoconceito de serem responsáveis pelas próprias decisões, pelas próprias vidas.

De acordo com a pesquisa analisada "Andragogia em ambientes virtuais de aprendizagem":

\begin{abstract}
Os adultos têm um autoconceito de serem responsáveis por suas ações, decisões, suas próprias vidas. De acordo com Knowles, Holton e Swanson (1998), uma vez atingido este autoconceito, desenvolvem uma profunda necessidade psicológica de serem reconhecidos pelos outros como capazes de se autodirigirem. São resistentes a situações nas quais sentem que os outros tentam lhes impor algo (CARDOSO, 2006, p. 33).
\end{abstract}

Conforme apresentado na teoria andragógica e no fragmento do trabalho de Cardoso (2006), o aprendiz adulto precisa primeiramente desenvolver uma autopercepção positiva sobre si mesmo, para, a partir desta, ser capaz de autodirecionar sua aprendizagem. Nesse sentido, o professor formador pode adotar atitudes que favoreçam que o aluno adulto se perceba como responsável pela própria aprendizagem, tais como, considerar a opinião e interesses dos alunos na condução da disciplina, incentivar a participação em sala, envolvê-los no planejamento e direção das atividades. Enfim, promover situações onde sejam dadas responsabilidades ao aprendiz adulto e ele seja induzido a ter uma participação mais ativa. Atitudes como essas podem contribuir para que o adulto aprendiz desenvolva um autoconceito de ser responsável pelas próprias decisões e pela própria aprendizagem, desenvolvendo também a capacidade de autodirecioná-la.

A autonomia foi destacada em quatro trabalhos analisados. De acordo com a perspectiva andragógica, a autonomia está fortemente ligada ao autoconceito do aprendiz e à aprendizagem autodirecionada, pois, se autoperceber como sujeito autônomo, responsável pelas próprias ações, é o que torna o adulto capaz de autodirecionar sua aprendizagem.

No trabalho selecionado "Formação de professores em processos andragógicos de ensino e aprendizagem", Dagostino (2012) argumenta sobre a autonomia:

Os alunos adultos já se encontram em uma fase da vida na qual possuem muitas responsabilidades, portanto, não são dependentes como as crianças. Nesse sentido, sentem a necessidade de tomar suas próprias decisões e autodirigir-se. Isso também acontece em seu processo de educação e aprendizagem (...) (DAGOSTINO, 2012, p. 5).

Ao contrário do que possa parecer, a autonomia não se refere a uma aprendizagem solitária ou totalmente independente. Os adultos, na perspectiva andragógica, desejam ser 
autônomos em seu processo de aprendizagem, mas a teoria esclarece que é de grande importância o papel do professor enquanto facilitador desse processo. O formador deve atuar estimulando a participação ativa do aprendiz, ele é alguém com mais conhecimentos e experiências na docência, que pode facilitar e mediar a aprendizagem do futuro professor.

Continuando nas categorias conceituais com aporte na Andragogia, a necessidade de saber foi destacada em quatro pesquisas do montante analisado. Essa categoria se refere ao fato de que os adultos necessitam saber por qual razão eles precisam aprender determinado conteúdo, antes de aprendê-lo.

Discorrendo sobre a necessidade de aprender, segundo a pesquisa "Formação de professores em processos andragógicos de ensino e aprendizagem": "o aluno adulto procura conhecer algo novo com uma intencionalidade interna que surge por uma necessidade que pode ser de ordem pessoal ou profissional" (DAGOSTINO, 2012, p. 4).

De acordo com esse fragmento, o interesse do adulto, sua necessidade de saber, é direcionado especialmente por situações de sua vida cotidiana. Ele tem sua necessidade de saber aguçada por demandas da sua vida diária, portanto, em ambiente acadêmico, é importante para o adulto que os conteúdos trabalhados tenham conexão com a realidade vivida por ele, especialmente no âmbito profissional.

Sendo assim, antes de iniciar um conteúdo é importante que o formador explique do que se trata e conscientize os aprendizes adultos da importância do aprendizado que será trabalhado.

A categoria Resolução de problemas se refere à aprendizagem que parte de situações e problemas reais vivenciados pelos adultos, diferente dos modelos tradicionais de ensino onde a aprendizagem é baseada em disciplinas e conteúdo padronizados.

De acordo com os postulados andragógicos de Knowles, Holton e Swanson (2009), o adulto não deve iniciar seu aprendizado por intermédio de "disciplinas" que podem um dia ser úteis em sua vida. É importante que a aprendizagem seja iniciada a partir de situações atuais da vida do adulto, de problemas que ele vivencia. O conhecimento, nesse modelo, deve ser orientado para a resolução de problemas reais do aprendiz e não para o acúmulo de conteúdo.

Essa categoria foi destacada em três trabalhos da nossa amostra investigada. O trabalho "Formação de professores em processos andragógicos de ensino e aprendizagem" ilustra a influência dessa categoria na aprendizagem do adulto:

(...) aprendem de maneira muito mais significativa e eficiente por meio da resolução de problemas e desafios do que através da simples transmissão tradicional de assuntos e conteúdos (DAGOSTINHO, 2012, p. 11).

A pesquisa analisada de Cardoso (2006) relaciona a categoria resolução de problemas à motivação do aluno adulto:

De modo geral, os adultos sentem-se motivados a aprender algo quando acreditam que o aprendizado irá ajudá-los na resolução de problemas e tarefas, ou 
quando percebem que o novo conhecimento se aplica às situações da vida real. Buscam assim melhores oportunidades, empregos, salários e qualidade de vida (CARDOSO, 2006, p. 60-61).

Os dois fragmentos apresentados demonstram a relevância que uma aprendizagem voltada para a resolução de problemas pode ter para o público adulto, possibilitando uma aprendizagem mais significativa, conforme argumenta Dagostino (2012), ou favorecendo a motivação dos alunos, como exposto por Cardoso (2006). A categoria resolução de problemas apareceu nas pesquisas como um elemento que influencia a aprendizagem do adulto e, portanto, deve ser considerado pelos educadores de pessoas adultas.

A categoria professor facilitador foi destacada em dois trabalhos analisados. Os pressupostos andragógicos postulados por Malcolm Knowles defendem que, na educação de pessoas adultas, o professor deve assumir o papel de orientador, um mediador, alguém que vai facilitar o processo de aprendizagem do aprendiz adulto. A andragogia defende uma relação horizontal entre professor e aprendiz, onde o professor deve respeitar a autonomia do seu aluno, sendo um motivador, um agente de transformação.

A respeito da atuação do professor como facilitador da aprendizagem, a dissertação selecionada de Dagostino (2011) traz:

\footnotetext{
O papel principal do professor que trabalha com alunos adultos é de facilitador e mediador da aprendizagem do mesmo, do que detentor do conhecimento de forma absoluta e acabada. O andragogo aponta e indica os caminhos que o aluno adulto deve percorrer para que este se aproprie cada vez mais de suas maneiras de aprender e incorpore de fato o conhecimento em questão. No modelo andragógico de ensino, o educador deve adotar um papel de provocador para que o aluno percorra seu caminho de forma cada vez mais autônoma, regulada e autodirigida, sendo capaz de se questionar e ir em busca das respostas, sendo capaz de aprender a aprender (DAGOSTINO, 2011, p. 98).
}

A teoria andragógica indica que assumindo a posição de facilitador, o professor atenderá melhor às características do indivíduo adulto, seu desejo de autonomia e autogerenciamento, e será capaz de promover uma aprendizagem mais significativa, pois coloca o aprendiz adulto como sujeito ativo, auxiliado pelo facilitador na construção do seu conhecimento.

\section{CONSIDERAÇõES FINAIS}

As nove categorias teórico-conceituais representativas da Andragogia identificadas nas pesquisas analisadas neste estudo nos revelam elementos influenciadores da aprendizagem do indivíduo adulto. Além de identificá-las, buscamos apresentar algumas formas de como cada uma dessas categorias pode ser empregada na aprendizagem do aluno adulto, apontando também algumas possibilidades de como cada uma dessas categorias pode contribuir no processo de formação de professores. 
Conforme observamos em nosso estudo, a Andragogia traz significativas considerações sobre a aprendizagem do adulto. Olhar para os docentes em formação como pessoas adultas demonstra ser um diferencial que vem a favorecer a aprendizagem dos licenciandos. De acordo com esta pesquisa, a Andragogia se configura em um tema a ser explorado pelo campo de formação de professores, inclusive no intuito de melhor entender a aplicação desses conceitos na realidade da prática docente.

\section{REFERÊNCIAS}

AZEVEDO, D. R. de. Educação à distância: estudo comparativo do perfil e motivações dos alunos das instituições de ensino superior e das organizações corporativas, 2009, 140p. Dissertação (Mestrado em Ciências Sociais) - Pontifícia Universidade Católica do Rio Grande do Sul - PUC, Porto Alegre, 2009.

CARDOSO, I. M. Andragogia em ambientes virtuais de aprendizagem, 2006, 158p. Dissertação (Mestrado em Educação) - Pontifícia Universidade Católica de Minas Gerais - PUC, Belo Horizonte, 2006.

CARVAlHO, J. A.; CARVALHO, M. P.; BARRETO, M. A. M.; ALVES, F. A. Andragogia: Considerações sobre a Aprendizagem do Adulto. Ensino, Saúde e Ambiente, Rio de Janeiro, v. 3, p. 78-90, 2010. Disponível em: <http://ensinosaudeambiente.uff.br/index. php/ensinosaudeambiente/article/view/108/107>. Acesso em: 5 out. 2016.

CYRINO, M.; SOUZA NETO, S.; SARTI, F, M. Ciclo de desenvolvimento do estágio na aprendizagem da docência. In: III Congresso Nacional de. Formação de Professores (CNFP). UNESP, Rio Claro, 2016.

DAGOSTINO, G. B. Formação de professores em processos andragógicos de ensino e aprendizagem, 2011, 109s. Dissertação (Mestrado em Educação) - Pontifícia Universidade Católica de São Paulo - PUC, São Paulo, 2011.

. Formação de professores em processos andragógicos de ensino e aprendizagem. In: XVI ENDIPE - Encontro Nacional de Didática e Prática de Ensino, 16, 2012, Campinas. Anais... Campinas: UNICAMP, 2012.

GARCÍA, C. M. Formação de professores: para uma mudança educativa. Porto: Porto Editora, 1999.

GIL, A. C. Como elaborar projetos de pesquisa, 4. ed. São Paulo: Ed. Atlas, 2002. GOLDENBERG, M. A arte de pesquisar. Rio de Janeiro: Record, 1999 (p. 11-73). 
KNOWLES, M. S.; HOLTON III, E. F.; SWANSON, R. A. Aprendizagem de resultados: uma abordagem prática para aumentar a efetividade da educação corporativa. Rio de Janeiro: Campus, 2009.

MIZUKAMI, M. G. N. et al. Escola e aprendizagem da docência: processos de investigação e formação. São Carlos: EDUUFSCar, 2002.

NOFFS, N. de A.; RODRIGUES, C. M. R. Andragogia na Psicopedagogia: a atuação com adultos. Rev. Psicopedagogia São Paulo, 2011; 28 (87): 283-292. Disponível em: <http:// pepsic.bvsalud.org/pdf/psicoped/v28n87/09.pdf > . Acesso em: 2 fev. 2017.

PERISSÉ, G. Andragogia - Disponível em: www.correiocidadania.com.br. Acessado em: 11 jan. 2017.

PLACCO, V. M. N. S.; SOUZA, V. L. T. (Orgs.). Aprendizagem do adulto professor, 2. ed. São Paulo: Loyola; 2015.

VAILLANT, D.; MARCELO, C. Ensinando a ensinar: as quatro etapas de uma aprendizagem, 1. ed. Curitiba: Editora Universidade Tecnológica Federal do Paraná, 2012.

VEIGA, I. ÁVILA, C. (Orgs.). Didática e Docência na Educação Superior: implicações para formação de professores. São Paulo: Papirus, 2012.

VOGT, M.; ALVES, E. Revisão teórica sobre a educação de adultos para uma aproximação com a andragogia. Revista do Centro de Educação, Santa Maria, v. 30, n. 2, p. 195-214, 2005.

\section{Dados das Autoras}

Amanda Cibele Soares Correio

Mestre em educação pela Universidade Federal de Viçosa.Viçosa/MG-Brasil. amanda cib@hotmail.com

\section{Rita de Cássia de Alcântara Braúna Correio}

Doutora em Educação. Professora do Departamento de Educação da Universidade Federal de Viçosa. Viçosa/MG-Brasil. rbrauna@ufv.br

\section{Ana Cláudia lopes Chequer Saraiva Correio}

Doutora em Educação. Professora do Departamento de Educação da Universidade Federal de Viçosa. Viçosa/MG-Brasil. aclaudia@ufv.br

Submetido em: $28-8-2018$

Aceito em: 18-1-2019 